\title{
Impact of HMGB1/TLR Ligand Complexes on HIV-1 Replication: Possible Role for Flagellin during HIV-1 Infection
}

\author{
Piotr Nowak, ${ }^{1}$ Samir Abdurahman, ${ }^{1}$ Annica Lindkvist, ${ }^{2}$ \\ Marius Troseid, ${ }^{3}$ and Anders Sönnerborg ${ }^{1,2}$ \\ ${ }^{1}$ Department of Infectious Diseases, Institution of Medicine, Karolinska University Hospital and Karolinska Institutet, \\ 14186 Stockholm, Sweden \\ ${ }^{2}$ Department of Clinical Microbiology, Institution of Laboratory Medicine, Karolinska University Hospital and Karolinska Institutet, \\ 14186 Stockholm, Sweden \\ ${ }^{3}$ Department of Infectious Diseases, Oslo University Hospital, Ullevål, 0424 Oslo, Norway
}

Correspondence should be addressed to Piotr Nowak, piotr.nowak@ki.se

Received 28 February 2012; Accepted 16 April 2012

Academic Editor: Giancarlo Ceccarelli

Copyright ( $\odot 2012$ Piotr Nowak et al. This is an open access article distributed under the Creative Commons Attribution License, which permits unrestricted use, distribution, and reproduction in any medium, provided the original work is properly cited.

Objective. We hypothesized that HMGB1 in complex with bacterial components, such as flagellin, CpG-ODN, and LPS, promotes HIV-1 replication. Furthermore, we studied the levels of antiflagellin antibodies during HIV-1-infection. Methods. Chronically HIV-1-infected U1 cells were stimulated with necrotic extract/recombinant HMGB1 in complex with TLR ligands or alone. HIV-1 replication was estimated by p24 antigen in culture supernatants 48-72 hours after stimulation. The presence of systemic anti-flagellin IgG was determined in $51 \mathrm{HIV}$-1-infected patients and 19 controls by immunoblotting or in-house ELISA. Results. Flagellin, LPS, and CpG-ODN induced stronger HIV-1 replication when incubated together with necrotic extract or recombinant HMGB1 than activation by any of the compounds alone. Moreover, the stimulatory effect of necrotic extract was inhibited by depletion of HMGB1. Elevated levels of anti-flagellin antibodies were present in plasma from HIV-1-infected patients and significantly decreased during 2 years of antiretroviral therapy. Conclusions. Our findings implicate a possible role of HGMB1bacterial complexes, as a consequence of microbial translocation and cell necrosis, for immune activation in HIV-1 pathogenesis. We propose that flagellin is an important microbial product, that modulates viral replication and induces adaptive immune responses in vivo.

\section{Introduction}

Antiretroviral therapy (ART) suppresses efficiently the replication of human immunodeficiency virus type 1 (HIV-1) to undetectable levels with standard techniques in most treated patients, but there is still an ongoing low-grade replication in most or all patients [1]. Also, immune activation is a central feature of progressive HIV-1 infection [2-4], and although the degree of immune activation is decreased during ART, it is not normalized [5]. The pathogenic mechanisms for the persistent immune activation remain further to be determined. This is especially important since studies suggest that the remaining immune activation may cause organ damage, for example, an increased risk for cardiovascular diseases and possibly neurocognitive dysfunction $[5,6]$.

The gastrointestinal (GI) immune system seems to play a central role in the pathogenesis of immune activation [7]. The early dramatic depletion of CD4+ T cells from the gut mucosa may drive immune activation, as this mucosal immune damage impairs the normal barrier function and allows increased translocation of bacterial products from the gut lumen into the circulation [8]. We and others have shown that microbial translocation is present in HIV-1 infection through increased plasma LPS levels in subjects with progressive disease and that the levels are decreased by ART [9-11]. 
Furthermore, we and others have implied that the alarmin high-mobility group binding 1 protein (HMGB1) modulates HIV-1 replication in vitro and contributes to the activation of immune system [12-14]. Thus, plasma HMGB1 levels are elevated in HIV-1-infected patients and reduced with effective ART $[11,15]$. HMGB1 is released from damaged or necrotic cells to the extracellular milieu, in which it may act as a potent proinflammatory marker by stimulating cytokine expression in monocytes and endothelial cells $[16,17]$. HMGB1 per se does not seem to have a proinflammatory activity $[18,19]$ but has a high affinity to form complexes with other molecules such as LPS and CpG-DNA [20]. These complexes are likely to bind to various receptors, including TLR4 and TLR9, and promote a large variety of inflammatory and immunological responses [20, 21].

The aim of our study was to explore whether complexes of HMGB1 and TLR ligands, such as flagellin, could synergistically induce HIV-1 replication in a promonocytic cell line.

\section{Methods}

2.1. Ethic Statement. All research involving human participants has been conducted according to the principles expressed in the Declaration of Helsinki. Patients gave their informed written consent and the study protocol was approved by the Regional Ethics Committee in Stockholm, Sweden (Dnr 2005/3:10).

2.2. Reagents. Lipopolysaccharide (LPS) and (phorbol-12myristate-13-acetate) PMA were obtained from Sigma (St. Louise, MO, USA), IL- $1 \beta$ from R\&D Systems (Minneapolis, MN, USA), and CpG-ODN type B (ODN2006), purified flagellin (S.typhimurium), and anti-flagellin (FliC) antibodies from InvivoGen (San Diego, CA, USA and Abcam, Cambridge, UK). Recombinant HMGB1 (HM-116) was purchased from HMGBiotech (Milan, Italy) or from R\&D systems (Minneapolis, MN, USA). We also used recombinant HMGB1 [19] that was a kind gift from Professor Helena Erlandsson-Harris CMM/KI, Stockholm.

2.3. Cell Cultures. U1 cells, a subclone derived from U937 cells, were obtained through the AIDS Research and Reference Reagent Program (NIAID, NIH). The U1 cells are chronically infected with HIV-1 and are characterized by low constitutive levels of virus expression that can be upregulated by several cytokines and phorbol esters. The cells were maintained in RPMI medium (Gibco) supplemented with 10\% fetal calf serum, glutamine, and antibiotics. Cells were seeded at 200000 cells/mL in 96-well plates and complexes/TLRligands/controls were added and incubated for 48 or 72 hours.

2.4. Patients. Patients $(n=51)$ given ART, followed at the Department of Infectious Diseases, Karolinska University Hospital, Stockholm, and 19 healthy controls were included. Patients' recruitment was based on sample availability as well as virologic response after 2 years of ART. Thirty-three individuals had undetectable viral load and 18 had detectable viraemia (nonresponders) after 2 years of treatment. This cohort (42 of 51 patients) has been described previously [11]. The age and sex distribution of the patients and controls was similar (median age 38 years, 52\% women).

2.5. Preparation of Necrotic Cell Extracts. Necrotic extracts were obtained as previously described [22]. Briefly, necrosis was induced in peripheral blood mononuclear cells (PBMCs) from healthy donors $\left(30 \times 10^{6}\right.$ cells $\left./ \mathrm{mL}\right)$ by exposing the cells to six cycles of freezing and thawing. Cell debris was removed by centrifugation and the supernatant was passed through a $0.2 \mu \mathrm{m}$ membrane and collected. The concentration of HMGB1 in necrotic extracts was $40 \mu \mathrm{g} / \mathrm{mL}$, as estimated by immunoblot (data not shown). Furthermore, $250 \mu \mathrm{L}$ of necrotic extract was incubated with polyclonal anti-HMGB1 antibodies (Abs) from ABCAM (Cambridge, UK). Samples were incubated at $4^{\circ} \mathrm{C}$ for 16 hours. As control, nonspecific Abs (Rabbit polyclonal IgG) was utilized. Immune complexes were removed by adding $25 \mu \mathrm{L}$ of Sepharose A/G to the extract, incubated for 1.5 hours at $4^{\circ} \mathrm{C}$, and centrifuged. The supernatant was collected and the procedure was repeated again with $25 \mu \mathrm{L}$ sepharose for 1 hour at $4^{\circ} \mathrm{C}$.

2.6. Preparation of HMGB1 Complexes. Necrotic extract or HMGB1was mixed with the TLR-ligands, LPS, CpG-ODN, IL- $1 \beta$, and flagellin in PBS in different concentrations and incubated for 16 hours at $4^{\circ} \mathrm{C}$. Concentrations are given in Figures 1-3. The suboptimal stimulatory concentrations (capable to trigger HIV replication from U1 cells) of necrotic extract as well as LPS, flagellin, CpG-ODN, and Il-1 $\beta$ were estimated in a series of experiments (data not included). Complexes were also mixed and denatured by heating at $95^{\circ} \mathrm{C}$ for five minutes to verify the stimulatory effect of complex formation on U1 cells.

2.7. Characterization of HMGB1 with Immunoblotting. Equal volumes of necrotic cell extracts, HMGB1-depleted necrotic cell extracts, as well as recombinant HMGB1 proteins were resolved on 10-20\% Tris/glycine gel and transferred onto nitrocellulose membrane (Invitrogen, Carlsbad, USA). The membranes were then incubated overnight with antiHMGB1 Abs at 1:2000 dilution. The following day, the membranes were incubated $1 \mathrm{~h}$ with horseradish-peroxidase (HRP-) conjugated secondary antibody (GE, Healthcare), raised against rabbit IgG at $1: 10,000$ dilution. The proteins were finally visualized using ECL reagents (GE, Healthcare).

2.8. Immunoblotting of Antiflagellin Antibodies. Approximately $1.88 \mu \mathrm{g}$ of recombinant flagellin was twofold serially diluted (4 series) and subjected to gel electrophoresis on $10-20 \%$ precasted SDS-PAGE gel (Invitrogen) in Tris/glycine/SDS buffer. Similarly, bacterial extracts of flagellated E. coli strain O126:H2 and aflagellate E. coli $\mathrm{O} 21: \mathrm{H}-$ (CCUG catalog number 11425 and 11326, kind gift from Professor Andrej Weintraub, Clinical Microbiology/KI, Stockholm) that were prepared freshly from an overnight inoculation were also resolved on SDS-PAGE gel as described previously. The proteins were then electroblotted onto iBlot 


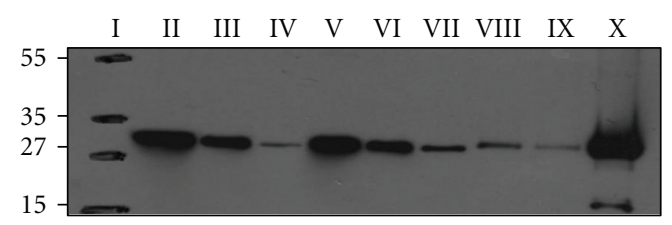

(a)

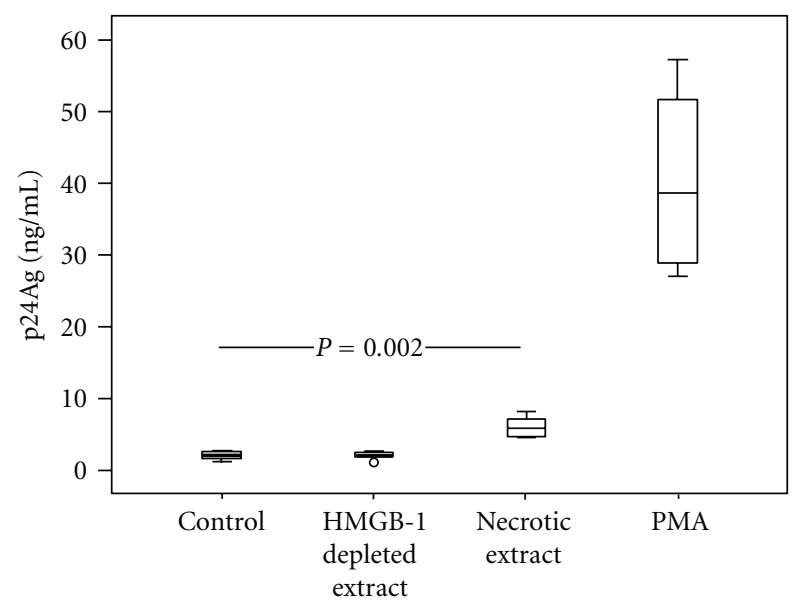

(b)

FIgURE 1: HMGB1 present in necrotic extract induces HIV-1 replication in U1 cells. (a) Western blot of cell supernatants (necrotic extracts) obtained after freeze-thawing cycles of peripheral blood mononuclear cells $(\mathrm{PBMC})\left(30 \times 10^{6}\right.$ cells $\left./ \mathrm{mL}\right)$ from healthy donors: Molecular weight marker (I); supernatants after immune depletion of HMGB1 with nonspecific rabbit polyclonal antibody (II); depletion with anti-HMGB1 antibody $-5 \mu \mathrm{g}$ (III) and $10 \mu \mathrm{g}$ (IV); necrotic extract loaded $20 \mu \mathrm{L}$ (V), $10 \mu \mathrm{L}$ (VI), and $5 \mu \mathrm{L}$ (VII); $100 \mathrm{ng}$ (VIII) and $75 \mathrm{ng}$ (IX) of recombinant HMGB1; cell debris (X). Numbers to the left depict positions of molecular mass markers (in $\mathrm{kDa}$ ). (b) Levels of HIV p24 protein in cell culture supernatants after $72 \mathrm{~h}$ incubation of U1 cells with necrotic extract (HMGB1 concentration $1 \mu \mathrm{g} / \mathrm{mL}$ ): HMGB1-depleted necrotic extract and mock cells. PMA served as a positive control $(20 \mathrm{nM})$. The levels of viral replication were approximately 2 -fold higher after stimulation by necrotic extract compared to the mock cells $(P=0.002)$. Results from three independent experiments in duplicates are presented.

gel transfer stacks nitrocellulose membranes, using the iBlot dry blotting system (Invitrogen), as recommended by the manufacturer. After blocking the nitrocellulose membranes for 1 hour in blocking buffer (PBS supplemented with $0.05 \%$ Tween and containing 10\% nonfat milk), the blots were probed with primary antibodies overnight at $4^{\circ} \mathrm{C}$ with a slow agitation. As primary antibody, serum from HIV-1infected or control subjects diluted 1:1000, monoclonal, or polyclonal anti-flagellin Abs was used. The following day, the membranes were washed with PBS containing $0.05 \%$ ( $\mathrm{vol} / \mathrm{vol}$ ) Tween and bound antibodies were then detected by using HRP-conjugated secondary Abs (Pierce) against human IgG in $1: 10,000$ dilution. Protein bands were visualized by chemiluminescence (Thermo Scientific). To confirm the protein bands, two immunoblotted membranes from HIV-1-infected patients and control subjects were stripped off and reprobed with mouse monoclonal antibody directed against flagellin. Bound antibodies were then detected by using an HRP-conjugated secondary antibody, raised against mouse (DAKO; $1: 4.000)$.

2.9. Specific and Total Antibodies Measurement. Antibody titers against flagellin, measles, and total IgG levels were assessed by ELISA. An in-house anti-flagellin-specific IgG ELISA was developed using purified flagellin monomers from S. typhimurium (InvivoGen). It has been previously shown that human sera have a similar recognition pattern of flagellin monomers whether isolated from flagellated E. coli or S. typhimurium [23]. Briefly, microwell plates (MWP) were coated overnight with purified flagellin from S. typhimurium (25 ng/well). The following day, plasma samples from HIV-1-infected and control subjects diluted 1:1000 were applied to wells coated with flagellin. After incubation and washing, the MWPs were incubated with HRP-conjuggated anti-human IgG. For total IgG ELISA, the manufacturer's procedure was followed (MABTECH, Nacka, Sweden). The Enzygnost Measeles virus IgG ELISA kit (Behring, Germany) was utilized for quantification of antimeasles antibodies.

2.10. Plasma HIV-1 RNA Quantification and CD4+/CD8+ TCell Counts. Plasma HIV-1 RNA levels (COBAS Amplicor test Roche Molecular Systems; USA; detection limit 40 copies/mL) and T-cell counts (flow cytometry) were evaluated as part of clinical routine.

2.11. HIV-1 Replication Assay. Supernatants were collected at indicated time points and tested for the presence of HIV p24 antigen with Architect i2000 HIV-1 Ag/Ab combo detection system (Abbott Diagnostics, Abbott Park, IL, USA). The p24 concentration was calculated based on the several standard dilutions of p24 protein included in each run.

2.12. Statistics. Data are presented as median, interquartile range, and total range. Differences between groups were analysed with the Mann-Whitney $U$-test, and intragroup changes from baseline to the end of the study were evaluated by Wilcoxon test. Jonckheere-Terpstra test was used for trend analyses and correlation analyses were performed using the Spearman method. A two-tailed significance level of 0.05 was used. The statistical analyses were performed with SPSS software, version 15.0 (SPSS Inc, Chicago, USA).

\section{Results}

3.1. Necrotic Cellular Extract Upregulates HIV-1 Replication in U1 Cells. To determine the impact of an endogenous signal, associated with cell injury, on HIV-1 replication, we generated soluble necrotic extracts from healthy donors PBMCs. Western blot confirmed the presence of large amounts of HMGB1 in the extracts. Additionally HMGB1depleted extracts were obtained by immune depletion utilizing specific anti-HMGB1 antibodies (Figure 1(a)). In the initial experiment, the U1 cells were exposed to necrotic 


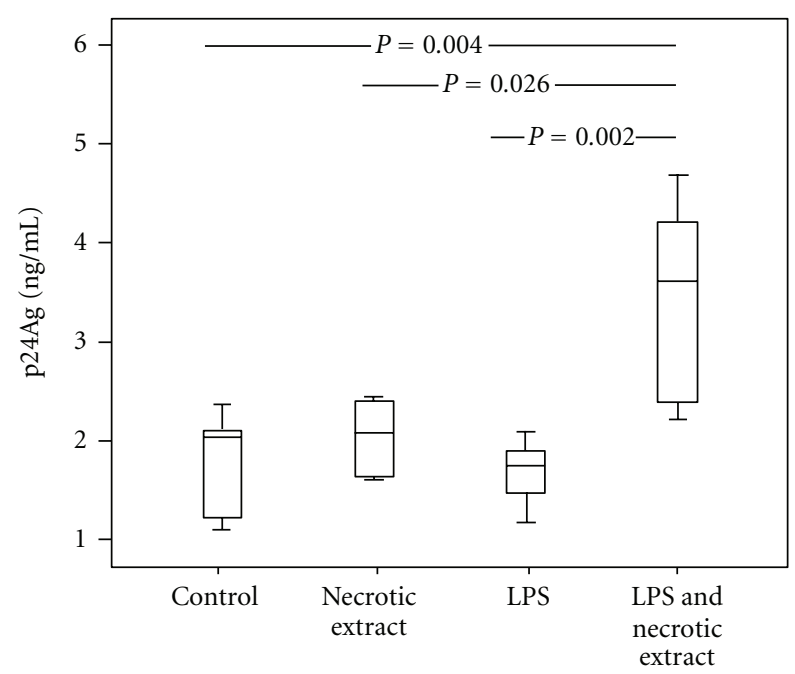

(a)

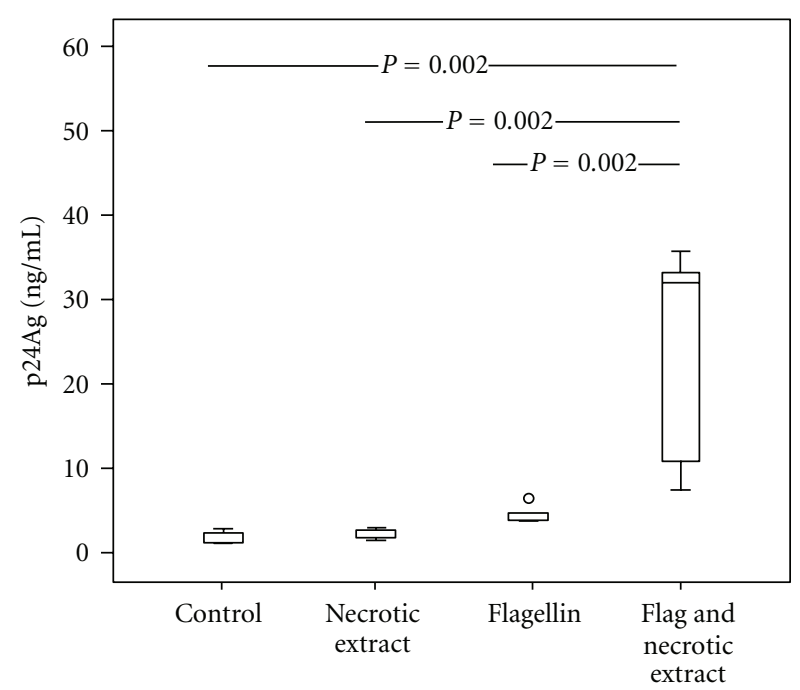

(c)

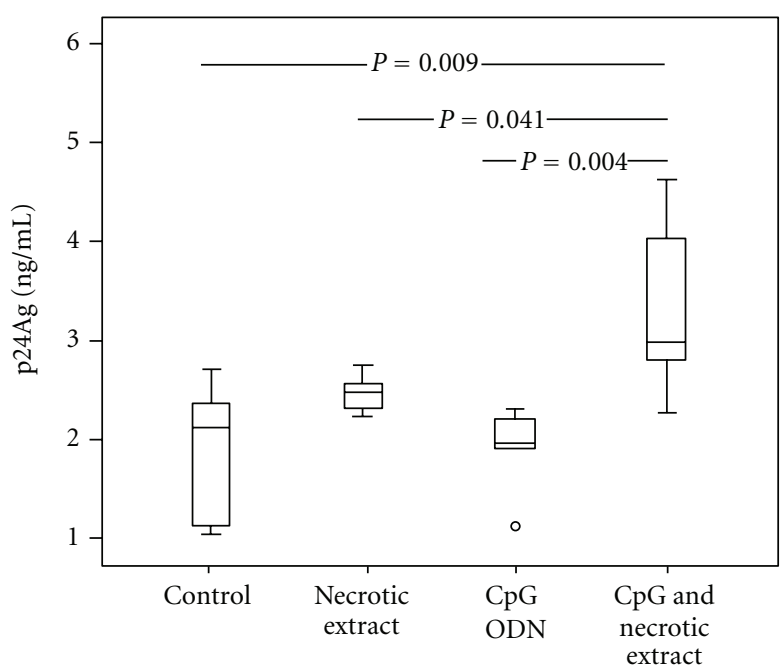

(b)

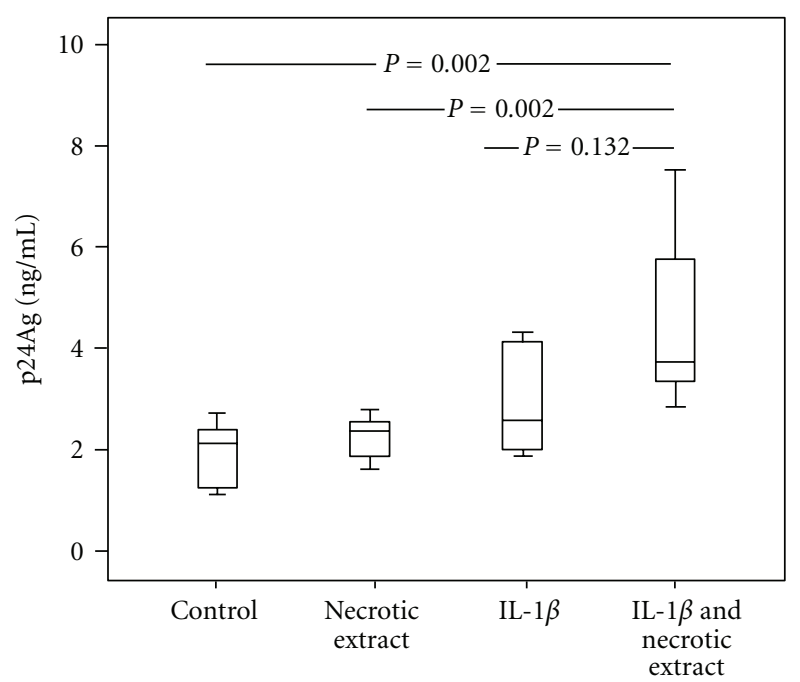

(d)

FIGURE 2: Necrotic extract and TLR-ligands in complexes upregulate viral replication in U1 cells. U1 cell cultures were stimulated with necrotic extract (HMGB1 concentration $1 \mu \mathrm{g} / \mathrm{mL}$ ) and Toll-like receptor ligands: LPS $10 \mathrm{ng} / \mathrm{mL}$ (a), CpG-ODN $1 \mu \mathrm{g} / \mathrm{mL}$ (b), flagellin $50 \mathrm{ng} / \mathrm{mL}$ (c), and IL-1 $\beta 0.25 \mathrm{ug} / \mathrm{mL}$ (d) alone or in complexes. Supernatants from mock cells served as controls. Supernatants were collected from cell cultures after 72 hours. Results from three independent experiments in duplicates are presented.

extract, HMGB1-depleted extract, and PMA, respectively. The HIV p24 antigen concentration in the cell supernatants was measured after 72 hours (Figure 1(b)). The levels of viral replication were approximately 2 -fold higher after stimulation by necrotic extract compared to the mock cells $(P=$ 0.002). The stimulation with PMA gave a 10 -fold higher viral replication than stimulation with necrotic extract. Notably, addition of necrotic extract depleted of HMGB1 did not result in an increase of viral replication, as compared to the controls, suggesting that HMGB1 crucially contributes to the stimulatory effect of the necrotic extract.

\subsection{Interacting Effect of TLR Ligands and Necrotic Extract on} HIV-1 Replication in U1 Cells. Thereafter, we stimulated the U1 cells with necrotic extract, TLR ligands (LPS, flagellin,
CpG-ODN), and IL-1 $\beta$ alone or with the complexes of necrotic extract and the TLR ligands or IL- $1 \beta$. Notably, stimulation with all the TLR ligands, in combination with necrotic extract, resulted in a higher viral replication than stimulation with necrotic extract or TLR ligands alone (Figure 2). Hence, stimulation with LPS, CpG-ODN and IL$1 \beta$ in complexes with necrotic extract resulted in a 1.5-2fold-increased viral replication compared to each component alone, whereas flagellin in combination with necrotic extract resulted in a 7 -fold increased replication compared to flagellin alone and a 13-fold-increased replication compared to necrotic extract alone. The preheating of complexes prior incubation with cells resulted in abrogation of stimulatory signal, implying that the active compound relies on intact protein structure (data not included). 


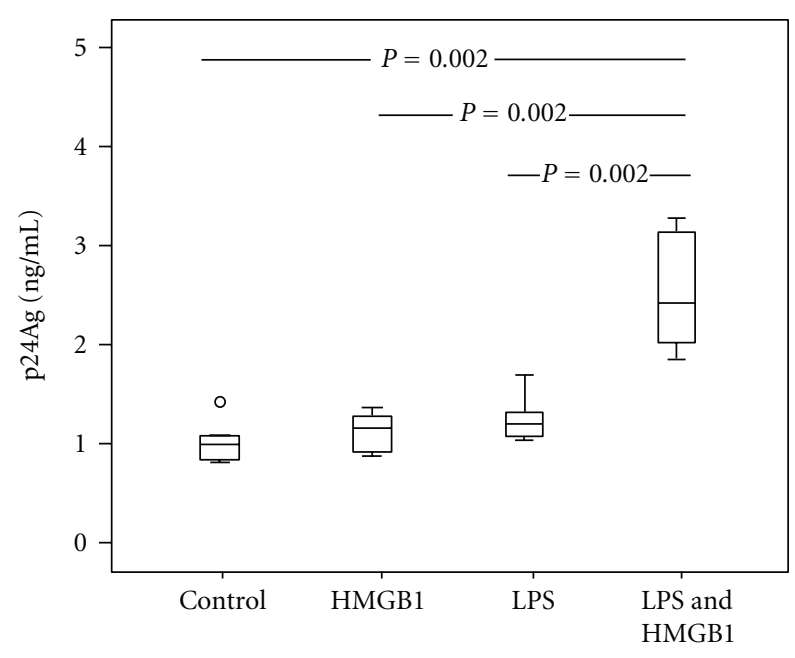

(a)

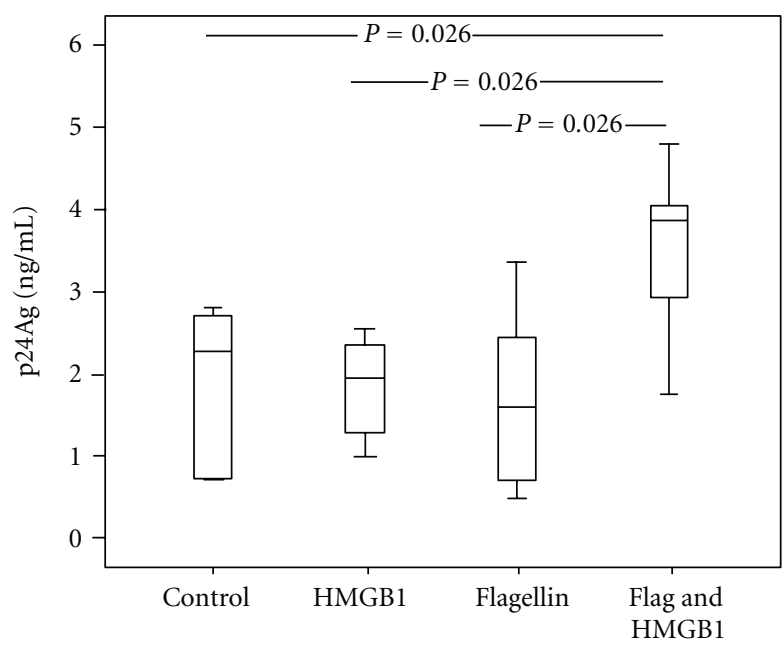

(c)

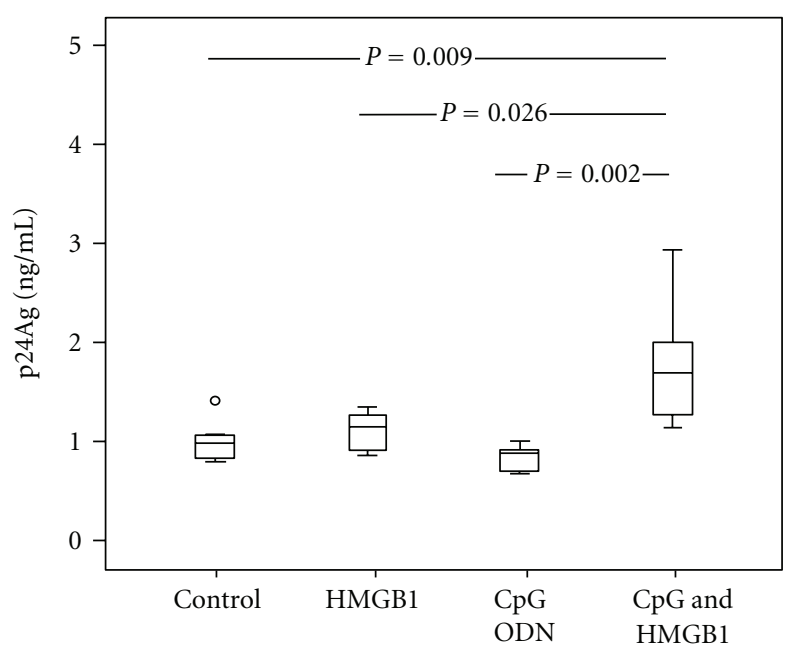

(b)

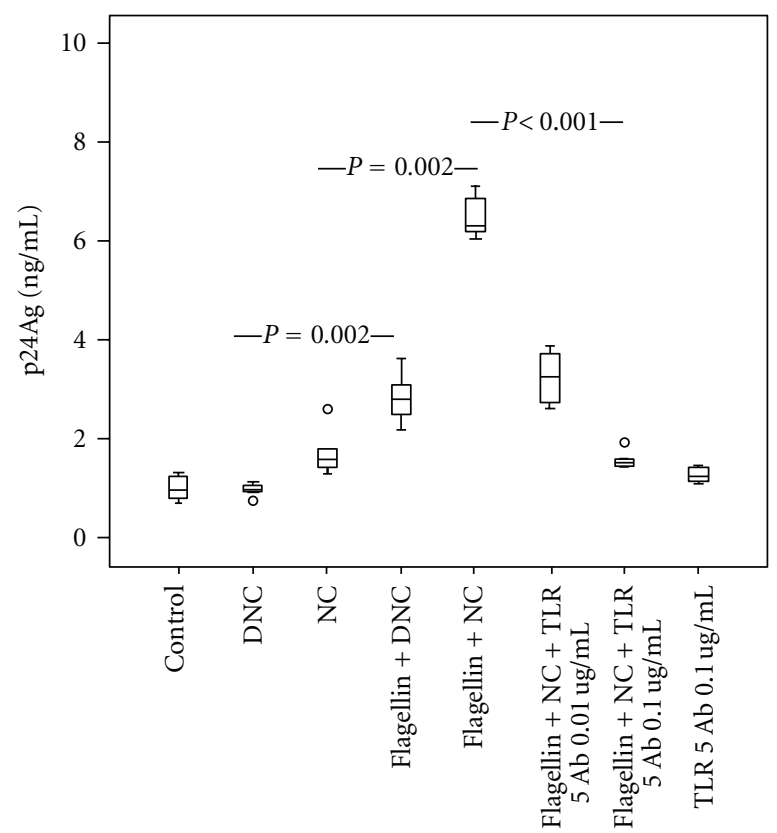

(d)

FIGURE 3: Interacting effect of recombinant HMGB1 and TLR-ligand complexes in U1 cells. Inhibition of flagellin complexes induced HIV-1 replication by anti-TLR5 antibodies. U1 cells were stimulated with recombinant HMGB1 ( $1 \mu \mathrm{g} / \mathrm{mL})$ and TLR ligands: LPS $10 \mathrm{ng} / \mathrm{mL}$ (a), CpG-ODN $1 \mu \mathrm{g} / \mathrm{mL}$ (b) and flagellin $10 \mathrm{ng} / \mathrm{mL}$ (c) alone or in complexes. (d) U1 cells were incubated with $0.1 \mathrm{and} 0.01 \mathrm{ug} / \mathrm{mL}$ anti-TLR5 antibodies (TLR5 Ab) for 1 hour and then exposed to necrotic extract (NC) and HMGB1-depleted necrotic extract (DNC), alone or in complexes with flagellin $(10 \mathrm{ng} / \mathrm{mL})$. HIV-1 replication was estimated after 48 hours of incubation. A dose-dependent inhibition of flagellinnecrotic extract complexes stimulatory effect is present in wells pretreated with anti-TLR5 antibodies $(P$ for trend $<0.001)$. Results from three independent experiments in duplicates are shown.

\subsection{Interacting Effect of TLR Ligands and HMGB1 on HIV-} 1 Replication in U1 Cells. In order to explore if HMGB1 could mimic the synergistic effects of necrotic extract-TLR ligands, we challenged the U1 cells with complexes consisting of HMGB1 and bacterial substances. Indeed, stimulation with microbial products (LPS, flagellin, or CpG-ODN) in combination with HMGB1 resulted in a higher viral replication than stimulation with HMGB1 or TLR ligands alone (Figures 3(a)-3(c)). Stimulation with LPS, flagellin, and $\mathrm{CPG}-\mathrm{ODN}$ in combination with HMGB1 resulted in a 1.5-2-fold-increased viral replication compared to each component alone, although the stimulatory effect was not as prominent as with TLR ligands in combination with necrotic extract.

3.4. Dose-Dependent Inhibition of Flagellin by Anti-TLR5. It is known that immune response to flagellin is mediated by TLR5. To investigate whether anti-TLR5 antibodies could block the inducing effects of flagellin, we first preincubated U1 cells with anti-TLR5 antibodies and subsequently added 
the necrotic extract complexed with flagellin. Flagellin in combination with HMGB1-depleted extract gave a 3-foldincreased viral replication compared to depleted extract alone, whereas flagellin in combination with necrotic extract gave a 4 -fold increase compared to necrotic extract alone (Figure $3(\mathrm{~d})$ ). Preincubation of U1 cells with anti-TLR5 antibodies before addition of necrotic extract-flagellin complexes resulted in a dose-dependent inhibition of this stimulatory effect ( $P$ for trend $<0.001)$. Addition of antiTLR5 antibodies alone did not affect viral replication.

\subsection{Detection of Antiflagellin Antibodies in HIV-1-Infected} Patients. Encouraged by the in vitro data we aimed to evaluate whether flagellin is a potentially important antigen in vivo during HIV-1 infection. Therefore, serum samples from HIV-1-infected patients and control subjects were used to measure the level of flagellin-specific antibodies by Western blot analysis. When diluted 1:1000, all of the sera samples from the HIV-1-infected patients analyzed exhibited easily detectable bands that recognized the first two dilutions of flagellin derived from S. typhimurium (Figure 4(a), upper panels). A relative increase in flagellin-specific IgG in HIV patients was observed if serum samples were diluted $1: 500$. In contrast, in only one control subject (CS\#2) flagellin was detected faintly at the highest dilution (Figure 4(a), lower panels). Although semiquantitative analysis of detected bands was not performed, the levels of flagellin-specific IgG observed were in all cases strikingly elevated in HIV-1infected patients. Similar pattern of anti-flagellin IgG was observed when plasma instead of sera was used. In order to address the specificity of the flagellin IgG, we subjected the bacterial lysates from flagellated and aflagellate E. coli to protein separation on the SDS-PAGE gel. The Western blotting with HIV-1 serum (as a primary antibody) showed similar pattern as when the polyclonal anti-flagellin antibody was used confirming that the specificity of the antibodies was not limited to the recombinant protein (Figure 4(b)).

Furthermore, we used the anti-flagellin ELISA to evaluate the levels of flagellin IgG in plasma of HIV-1-infected patients before and after two years of ART. At baseline significantly elevated levels of flagellin antibodies were found in HIV-1-infected patients as compared to controls $(P<0.001)$ (Figure 5(a)). This difference persisted $(P<$ $0.001)$ when the flagellin antibodies were adjusted to the total IgG (Figure 5(b)), suggesting that the elevation of flagellin antibodies was not due to hypergammaglobulinemia. Moreover, analysis of antimeasles antibodies in 10 patients with severe immune deficiency (CD4+ Tcell counts $\leq 200$ ) supported that the elevation of the flagellin antibodies was not caused by polyclonal activation Supplementary Table 1 (see supplementary material available online at doi:10.1155/2012/263836). The levels of flagellin IgG, total IgG, and the ratio flagellin IgG/total IgG were significantly reduced after two years of ART for the whole group $(P<0.001, P=0.03$, and $P<$ 0.001 , resp. Figures $5(\mathrm{a})-5(\mathrm{c}))$. Additionally a significant reduction of flagellin IgG levels was observed also when the patients were subdivided into those with successful ART and the nonresponders who had remaining low levels of viral replication two years after initiating the ART $(P=0.009$; $P=0.001$, resp.). The total IgG levels after ART did not decrease in nonresponders as they did in successfully treated patients $(P<0.001)$ (data not shown).

We found no correlation between the levels of flagellin IgG and the viral load nor the CD4/CD8 T-cell counts. In contrast, among the subgroup of 42 patients in whom we had earlier analysed HGMB1 and LPS in plasma, significant correlations were found between the levels of flagellin IgG and LPS ( $r=0.32 ; P=0.02)$ as well as between the flagellin IgG/total IgG ratio and LPS $(r=0.25 ; P=0.007)$ (data not shown).

\section{Discussion}

Microbial translocation has been described in different conditions like inflammatory bowel disease, neutropenia, and chronic viral infections $[6,24]$. In HIV-1 infection, the proof for the translocation of bacterial products is based mainly on LPS data $[9,11,25,26]$. However, the original observation that increased LPS levels were associated with both activated memory CD8+ T cells and enhanced IFN- $\alpha$ levels implies the involvement of other factors [9].

We therefore hypothesized that HMGB1 could be such a link between the microbial products and hyperinflammation [27]. Mounting evidence shows that HMGB1 does not act alone but forms stable potent proinflammatory complexes with other molecules, such as bacterial products or single stranded DNA [18-20, 28]. Since we have earlier shown that HMGB1 alone activates latent HIV-1 replication in vitro [12], we decided to expand our analysis to the effect of HGMB1 in complexes with bacterial products. Here, we present that HMGB1 in complex with the TLR ligands (LPS, CpG-ODN, flagellin) and IL- $1 \beta$ induce viral replication in a promonocytic cell line, U1 cells. The data obtained with both the HMGB1 derived from necrotic extract as well as recombinant protein yielded similar results, although the stimulatory signals associated with necrotic HMGB1 were more potent. This is not surprising as other endogenous danger signals should be anticipated in this process [20]. The reduction of the stimulatory effect by depletion of HGMB1 also supports our hypothesis that HMGB1 is an important component of these complexes.

These in vitro findings brought our attention to flagellin as a potent activator of $\mathrm{HIV}-1$ replication alone or in complexes with HMGB1. Bacterial flagellins are present in all motile bacteria and play an important role in mediating gut inflammation associated with infection by enteric pathogens or in inflammatory bowel diseases [29]. Their proinflammatory activity is exerted mainly through TLR5 [30, 31]. It has been recently demonstrated that flagellin is the major antigen activating innate and adaptive immune response in intestinal inflammation observed in Crohn's disease [32, 33]. Disruption of the intestinal barrier promotes translocation of flagellated commensal bacteria across the epithelium driving the activation of innate immune cells residing in the lamina propria. This phenomenon results also in abnormal exposure 

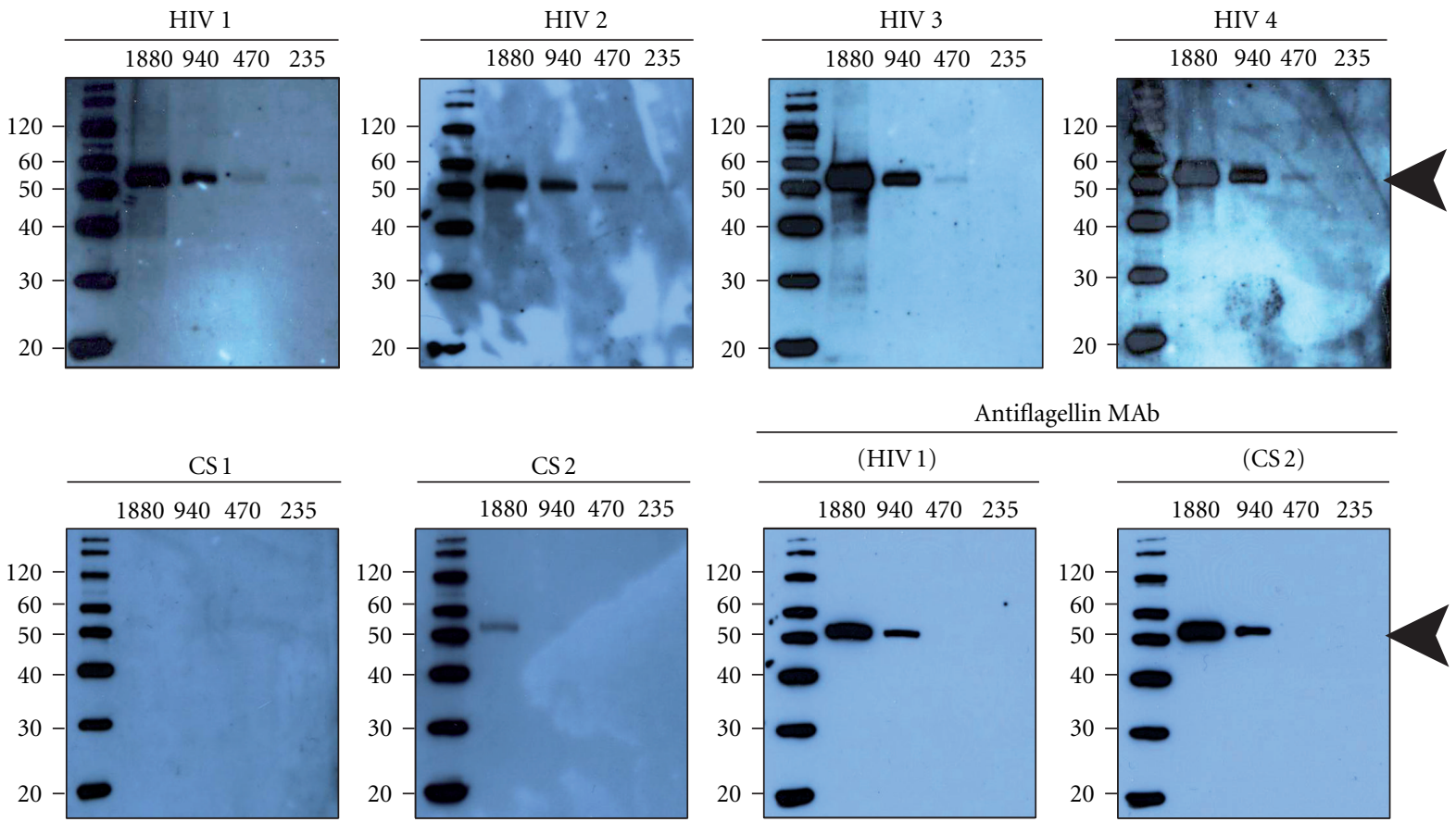

(a)

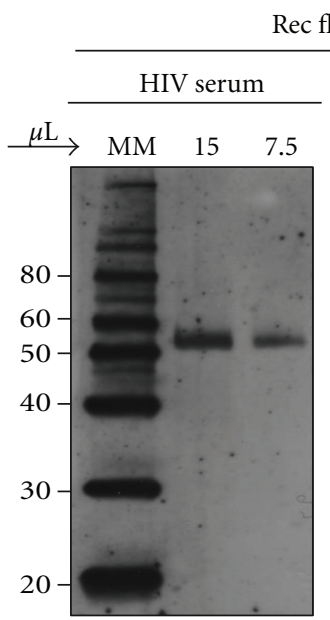

Rec flagellin

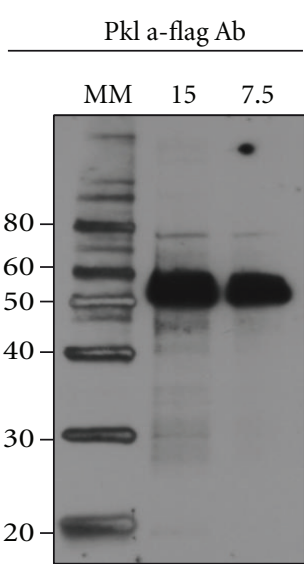

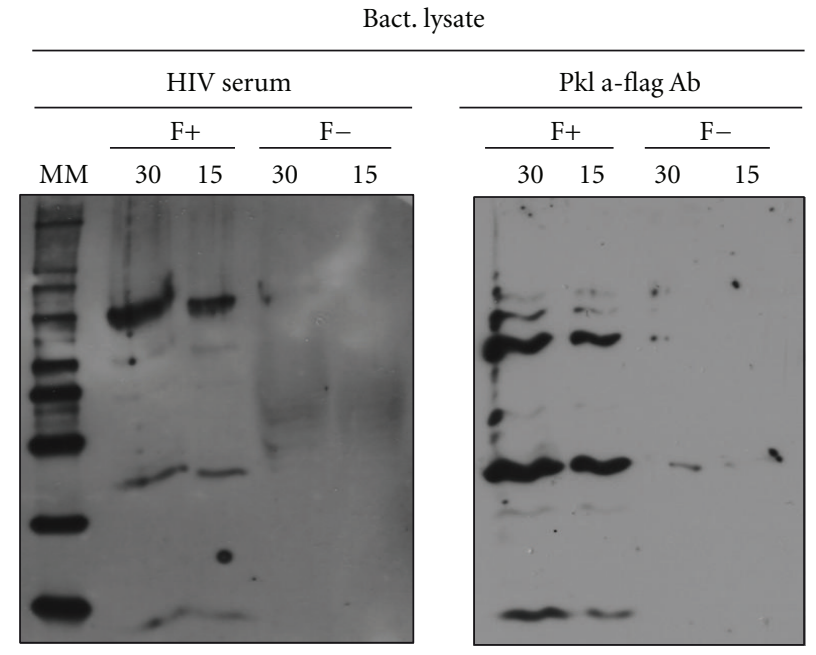

(b)

FIgURE 4: HIV-1-infected patients exhibit elevated levels of flagellin-specific antibodies. (a) Approximately $1.8 \mu \mathrm{g}$ of recombinant flagellin was twofold serially diluted (4 series) and resolved on 10-20\% SDS-PAGE gel, transferred onto a nitrocellulose membrane, and detected with immunoblot assay. Serum from HIV-1-infected or control subjects diluted 1:1000 was used as a primary antibody. Each panel is a separate immunoblot of the same recombinant flagellin detected with serum from HIV-1 patients (HIV 1, HIV 2, HIV 3, HIV 4) or control subjects (CS 1, CS 2). To confirm equal sample loading and protein transfer, immunoblotted membranes from HIV 1 and CS 2 were stripped off and reprobed with monoclonal antibody directed against flagellin (blots in the lower panel). The experiments were performed using sera from ten HIV-1-infected patients and four control subjects. These presented data are representative for all immunoblots. The position of recombinant flagellin protein is indicated with an arrow to the right. Numbers to the left depict positions of molecular mass markers (in kDa). (b) Recombinant flagellin (column 1) and lysates of flagellated or aflagellate E. coli (columns 3 and 4) were subjected to SDS-PAGE and immunoblotted using serum from HIV infected patient (column 1 and 3, diluted $1: 1000$ ) as primary antibody or polyclonal anti-flagellin antibody (columns 2 and 4, diluted $1: 1000$ ). The membrane in column 1 was stripped off and reprobed with polyclonal antiflagellin antibody (column 2). The numbers above the figures indicate the amount of sample loaded in each well (in $\mu \mathrm{L}$ ). MM, magic marker (Invitrogen); F+: flagellated; F-: aflagellate whole bacterial lysate; Pkl: polyclonal; Ab: antibody. Numbers to the left depict positions of molecular mass markers (in $\mathrm{kDa}$ ). 


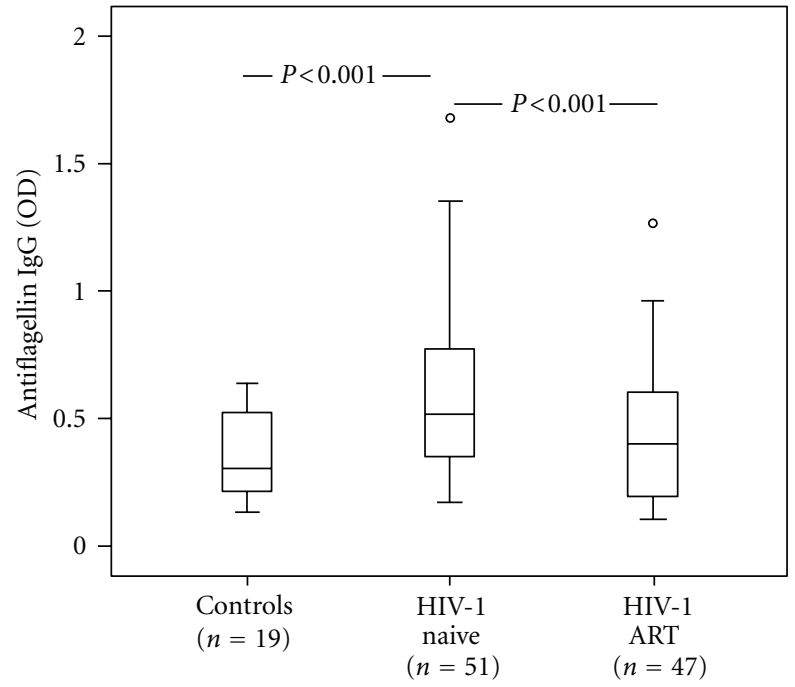

(a)

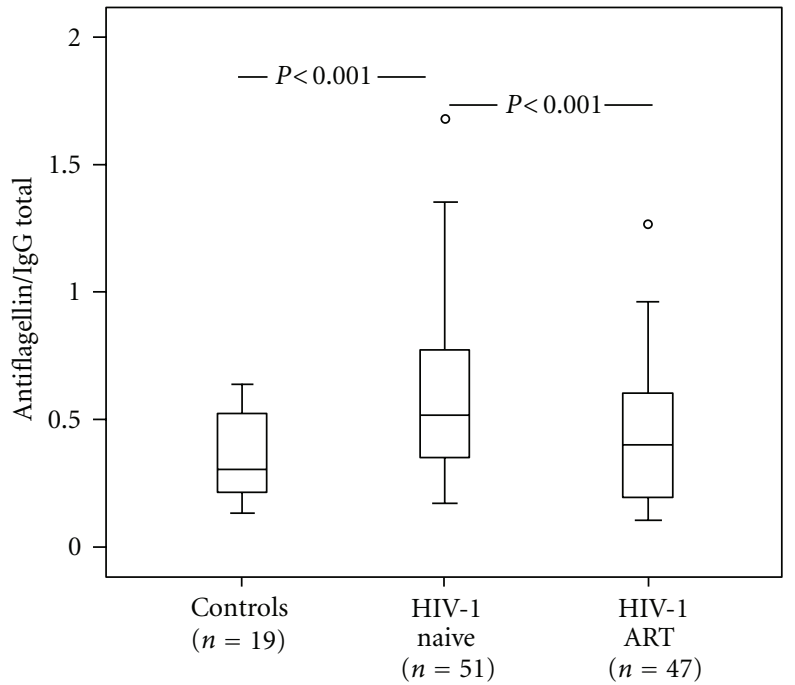

(b)

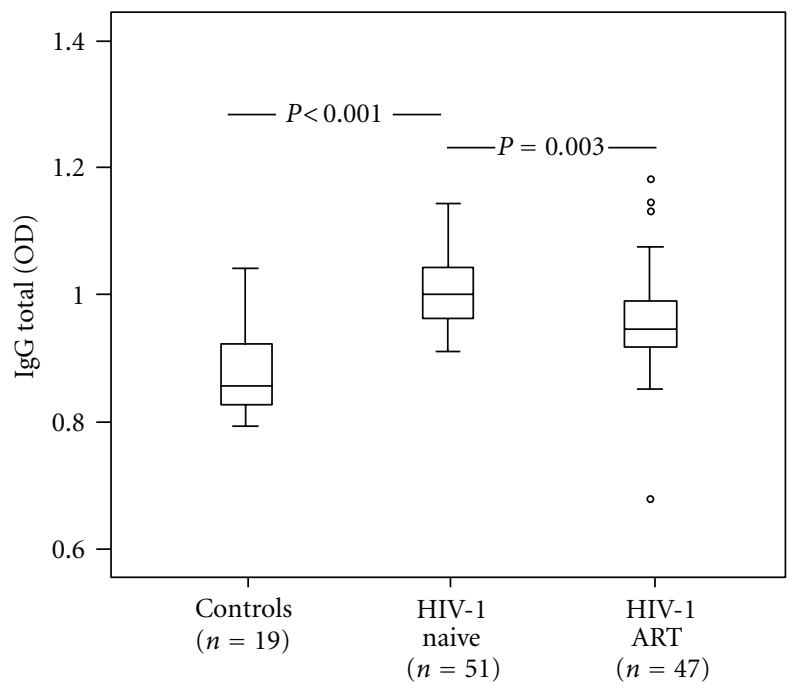

(c)

FIGURE 5: Elevated levels of anti-flagellin IgG are reduced during ART. Plasma levels (OD) of anti-flagellin IgG (a), ratio anti-flagellin IgG/total IgG (b), and total IgG (c) in healthy controls, HIV-1-infected individuals before (= naïve) and after two years of ART (antiretroviral therapy). The plasma samples were diluted 1:1000. The data are presented as median $25-75$ interquartile range and total range. $P$ values refer to intergroup differences.

of immune cells to flagellin, a process that may influence the balance and function of the different T-cell subsets present in the gut-associated immune system (GALT) and promote inflammation $[29,34]$.

The contribution of flagellin to immune activation during HIV-1 infection has been anticipated [7], but the data are scarce. Thus, exposure of PBMCs to flagellin resulted in activation of $\mathrm{T}$ cells predominantly of central memory and effector memory phenotype [35]. Moreover, flagellin is able to induce HIV-1 gene expression in resting memory CD4+ T cells that are considered as a key cellular HIV-1 reservoir in infected individuals [36].
Our in vitro and in vivo findings are clearly in line with the hypothesis of an important role of flagellin in HIV-1 pathogenesis. Thus, we demonstrated that flagellin complexes are able to significantly stimulate the HIV-1 replication, at least from cells of monocytic origin. Furthermore, our finding that elevated levels of anti-flagellin IgG are present in HIV-1-infected individuals anticipates that this observation has in vivo implications. Hence, we show not only presence of elevated levels of flagellin antibodies before the initiation of ART but also a reduction after two years of ART suggesting decreased exposure to the antigen probably due to partial restoration of gut-blood barrier [25, 37]. 
The hypergammaglobulinemia present during the HIV-1 infection cannot be solely responsible for the elevation of flagellin IgG levels as the normalisation to the $\operatorname{IgG}$ did not influence the results.

An elevated adaptive immune response to flagellin has been previously observed in conditions associated with gut barrier dysfunction such as Crohn's disease and short bowel syndrome $[23,24]$ and relates to the severity of Crohn's disease [38]. Also, Kamat et al. [39] reported recently the presence of a subgroup of anti-flagellin antibodies (antiCBir1) in 4/26 HIV-1-infected patients with CD4+ T-cells counts $<300$ cells/ul and high LPS levels. The CBir 1 flagellin has been identified as an immune dominant flagellin in Crohn's disease and linked to Clostridia species. Interestingly a recently presented work has shown alterations in bacterial composition of microbiota during HIV-1 infection with significantly lower ratio of Clostridia taxa in faeces obtained from HIV-1-infected patients as compared to controls [40]. Although our assay is based on the recognition of Salmonella typhimurium flagellin which spans the two well conserved $\mathrm{N}$ - and C-terminal domains of flagellin [41] enabling us the detection of broader range of flagellin antibodies, additional studies are needed to determine the antibody specificity. Furthermore, our results deserve future studies of adaptive flagellin immune response in a larger cohort of HIV-1infected individuals.

In summary, the novelty of our findings is that the bacterial products and HMGB1 form active complexes which can efficiently not only create a proinflammatory milieu but also directly trigger viral replication in infected cells. This synergistic effect may require lower levels of the interacting substances when present in complexes, as suggested by others [19]. We also report that flagellin has to be considered as a microbial product that can contribute to the immune activation during the HIV-1 infection. The formation of HMGB1/TLR ligand complexes has direct implications on immune activation, particularly in late stage of disease, where cell destruction and necrosis are dominant phenomena due to CD4+ T-cell loss, opportunistic infections, and other pathological conditions [27].

\section{Acknowledgments}

The study was supported by the Swedish Medical Research Council, Stockholm County Council, Swedish Physicians against AIDS, Swedish Medical Society (SLS), and Swedish Society for Medical Research (SSMF for Piotr Nowak). Data included in the paper were presented in part at the CROI meeting 2010 and 2011.

\section{References}

[1] J. B. Dinoso, S. Y. Kim, A. M. Wiegand et al., "Treatment intensification does not reduce residual HIV-1 viremia in patients on highly active antiretroviral therapy," Proceedings of the National Academy of Sciences of the United States of America, vol. 106, no. 23, pp. 9403-9408, 2009.

[2] M. D. Hazenberg, S. A. Otto, B. H. B. Van Benthem et al., "Persistent immune activation in HIV-1 infection is associated with progression to AIDS," AIDS, vol. 17, no. 13, pp. 18811888, 2003.

[3] M. Hellerstein, M. B. Hanley, D. Cesar et al., "Directly measured kinetics of circulating $\mathrm{T}$ lymphocytes in normal and HIV-1-infected humans," Nature Medicine, vol. 5, no. 1, pp. 83-89, 1999.

[4] J. V. Giorgi, L. E. Hultin, J. A. McKeating et al., "Shorter survival in advanced human immunodeficiency virus type 1 infection is more closely associated with $\mathrm{T}$ lymphocyte activation than with plasma virus burden or virus chemokine coreceptor usage," Journal of Infectious Diseases, vol. 179, no. 4, pp. 859-870, 1999.

[5] S. G. Deeks and A. N. Phillips, "HIV infection, antiretroviral treatment, ageing, and non-AIDS related morbidity," Bratislava Medical Journal, vol. 338, article a3172, 2009.

[6] J. M. Brenchley, D. A. Price, and D. C. Douek, "HIV disease: fallout from a mucosal catastrophe?" Nature Immunology, vol. 7, no. 3, pp. 235-239, 2006.

[7] J. M. Brenchley and D. C. Douek, "The mucosal barrier and immune activation in HIV pathogenesis," Current Opinion in HIV and AIDS, vol. 3, no. 3, pp. 356-361, 2008.

[8] J. M. Brenchley and D. C. Douek, "HIV infection and the gastrointestinal immune system," Mucosal Immunology, vol. 1, no. 1, pp. 23-30, 2008.

[9] J. M. Brenchley, D. A. Price, T. W. Schacker et al., "Microbial translocation is a cause of systemic immune activation in chronic HIV infection," Nature Medicine, vol. 12, no. 12, pp. 1365-1371, 2006.

[10] S. Baroncelli, C. M. Galluzzo, M. F. Pirillo et al., "Microbial translocation is associated with residual viral replication in HAART-treated HIV+ subjects with $<50$ copies/ml HIV-1 RNA," Journal of Clinical Virology, vol. 46, no. 4, pp. 367-370, 2009.

[11] M. Trøseid, P. Nowak, J. Nyström, A. Lindkvist, S. Abdurahman, and A. Sönnerborg, "Elevated plasma levels of lipopolysaccharide and high mobility group box-1 protein are associated with high viral load in HIV-1 infection: reduction by 2 -year antiretroviral therapy," AIDS, vol. 24, no. 11, pp. 1733-1737, 2010.

[12] P. Nowak, B. Barqasho, C. J. Treutiger et al., "HMGB1 activates replication of latent HIV-1 in a monocytic cell-line, but inhibits HIV-1 replication in primary macrophages," Cytokine, vol. 34, no. 1-2, pp. 17-23, 2006.

[13] S. Thierry, J. Gozlan, A. Jaulmes et al., "High-mobility group box 1 protein induces HIV-1 expression from persistently infected cells," AIDS, vol. 21, no. 3, pp. 283-292, 2007.

[14] L. Cassetta, O. Fortunato, L. Adduce et al., "Extracellular high mobility group box-1 inhibits R5 and X4 HIV-1 strains replication in mononuclear phagocytes without induction of chemokines and cytokines," AIDS, vol. 23, no. 5, pp. 567-577, 2009.

[15] P. Nowak, B. Barqasho, and A. Sönnerborg, "Elevated plasma levels of high mobility group box protein 1 in patients with HIV-1 infection," AIDS, vol. 21, no. 7, pp. 869-871, 2007.

[16] U. Andersson, H. Wang, K. Palmblad et al., "High mobility group 1 protein (HMG-1) stimulates proinflammatory cytokine synthesis in human monocytes," Journal of Experimental Medicine, vol. 192, no. 4, pp. 565-570, 2000.

[17] C. Fiuza, M. Bustin, S. Talwar et al., "Inflammation-promoting activity of HMGB1 on human microvascular endothelial cells," Blood, vol. 101, no. 7, pp. 2652-2660, 2003.

[18] A. Rouhiainen, S. Tumova, L. Valmu, N. Kalkkinen, and H. 
Rauvala, "Pivotal advance: analysis of proinflammatory activity of highly purified eukaryotic recombinant HMGB1 (amphoterin)," Journal of Leukocyte Biology, vol. 81, no. 1, pp. 49$58,2007$.

[19] H. S. Hreggvidsdottir, T. Östberg, H. Wähämaa et al., "The alarmin HMGB1 acts in synergy with endogenous and exogenous danger signals to promote inflammation," Journal of Leukocyte Biology, vol. 86, no. 3, pp. 655-662, 2009.

[20] M. E. Bianchi, "HMGB1 loves company," Journal of Leukocyte Biology, vol. 86, no. 3, pp. 573-576, 2009.

[21] S. Ivanov, A. M. Dragoi, X. Wang et al., "A novel role for HMGB1 in TLR9-mediated inflammatory responses to CpGDNA," Blood, vol. 110, no. 6, pp. 1970-1981, 2007.

[22] B. Barqasho, P. Nowak, S. Abdurahman, L. Walther-Jallow, and A. Sönnerborg, "Implications of the release of highmobility group box 1 protein from dying cells during human immunodeficiency virus type 1 infection in vitro," Journal of General Virology, vol. 91, no. 7, pp. 1800-1809, 2010.

[23] S. V. Sitaraman, J. M. Klapproth, D. A. Moore et al., "Elevated flagellin-specific immunoglobulins in Crohn's disease," American Journal of Physiology, vol. 288, no. 2, pp. G403-G406, 2005.

[24] T. R. Ziegler, M. Luo, C. F. Estívariz et al., "Detectable serum flagellin and lipopolysaccharide and upregulated anti-flagellin and lipopolysaccharide immunoglobulins in human short bowel syndrome," American Journal of Physiology, vol. 294, no. 2, pp. R402-R410, 2008.

[25] W. Jiang, M. M. Lederman, P. Hunt et al., "Plasma levels of bacterial DNA correlate with immune activation and the magnitude of immune restoration in persons with antiretroviraltreated HIV infection," Journal of Infectious Diseases, vol. 199, no. 8, pp. 1177-1185, 2009.

[26] N. G. Sandler, H. Wand, A. Roque et al., "Plasma levels of soluble CD14 independently predict mortality in HIV infection," Journal of Infectious Diseases, vol. 203, no. 6, pp. 780-790, 2011.

[27] M. Troseid, A. Sönnerborg, and P. Nowak, "High mobility group box protein-1 in HIV-1 infection: connecting microbial translocation, cell death and immune activation," Current HIV Research, vol. 9, no. 1, pp. 6-10, 2011.

[28] J. Tian, A. M. Avalos, S. Y. Mao et al., “Toll-like receptor 9dependent activation by DNA-containing immune complexes is mediated by HMGB1 and RAGE," Nature Immunology, vol. 8, no. 5, pp. 487-496, 2007.

[29] M. Vijay-Kumar and A. T. Gewirtz, "Flagellin: key target of mucosal innate immunity," Mucosal Immunology, vol. 2, no. 3, pp. 197-205, 2009.

[30] F. Hayashi, K. D. Smith, A. Ozinsky et al., "The innate immune response to bacterial flagellin is mediated by Toll-like receptor 5," Nature, vol. 410, no. 6832, pp. 1099-1103, 2001.

[31] M. Vijay-Kumar, J. D. Aitken, and A. T. Gewirtz, "Toll like receptor-5: protecting the gut from enteric microbes," Seminars in Immunopathology, vol. 30, no. 1, pp. 11-21, 2008.

[32] M. J. Lodes, Y. Cong, C. O. Elson et al., "Bacterial flagellin is a dominant antigen in Crohn disease," Journal of Clinical Investigation, vol. 113, no. 9, pp. 1296-1306, 2004.

[33] M. Vijay-Kumar and A. T. Gewirtz, "Role of flagellin in Crohn's disease: emblematic of the progress and enigmas in understanding inflammatory bowel disease," Inflammatory Bowel Diseases, vol. 15, no. 5, pp. 789-795, 2009.

[34] A. T. Gewirtz, T. A. Navas, S. Lyons, P. J. Godowski, and J. L. Madara, "Cutting edge: bacterial flagellin activates basolaterally expressed TLR5 to induce epithelial proinflammatory gene expression," Journal of Immunology, vol. 167, no. 4, pp. 1882-1885, 2001.
[35] N. Funderburg, A. A. Luciano, W. Jiang, B. Rodriguez, S. F. Sieg, and M. M. Lederman, "Toll-like receptor ligands induce human T cell activation and death, a model for HIV pathogenesis," PLoS ONE, vol. 3, no. 4, Article ID e1915, 2008.

[36] S. Thibault, M. Imbeault, M. R. Tardif, and M. J. Tremblay, "TLR5 stimulation is sufficient to trigger reactivation of latent HIV-1 provirus in T lymphoid cells and activate virus gene expression in central memory CD4+ T cells," Virology, vol. 389, no. 1-2, pp. 20-25, 2009.

[37] H. J. Epple, T. Schneider, H. Troeger et al., "Impairment of the intestinal barrier is evident in untreated but absent in suppressively treated HIV-infected patients," Gut, vol. 58, no. 2, pp. 220-227, 2009.

[38] S. R. Targan, C. J. Landers, H. Yang et al., "Antibodies to CBir1 flagellin define a unique response that is associated independently with complicated Crohn's disease," Gastroenterology, vol. 128, no. 7, pp. 2020-2028, 2005.

[39] A. Kamat, P. Ancuta, R. S. Blumberg, and D. Gabuzda, "Serological markers for inflammatory bowel disease in aids patients with evidence of microbial translocation," PLoS ONE, vol. 5, no. 11, Article ID e15533, 2010.

[40] E. Collin, C.-S. Li, Z.-M. Ma, H. Overman, and T. Knight, "Shifts in proportions of higher-taxa bacterial orders measured by $16 \mathrm{~S}$ rDNA PCR in the stools of HIV patients following ART and correlations with HIV immunopathogenesis," in Proceedings of the 18th Conference on Retroviruses and Opportunistic Infections, Boston, Mass, USA, 2011.

[41] R. M. Macnab, "How bacteria assemble flagella," Annual Review of Microbiology, vol. 57, pp. 77-100, 2003. 

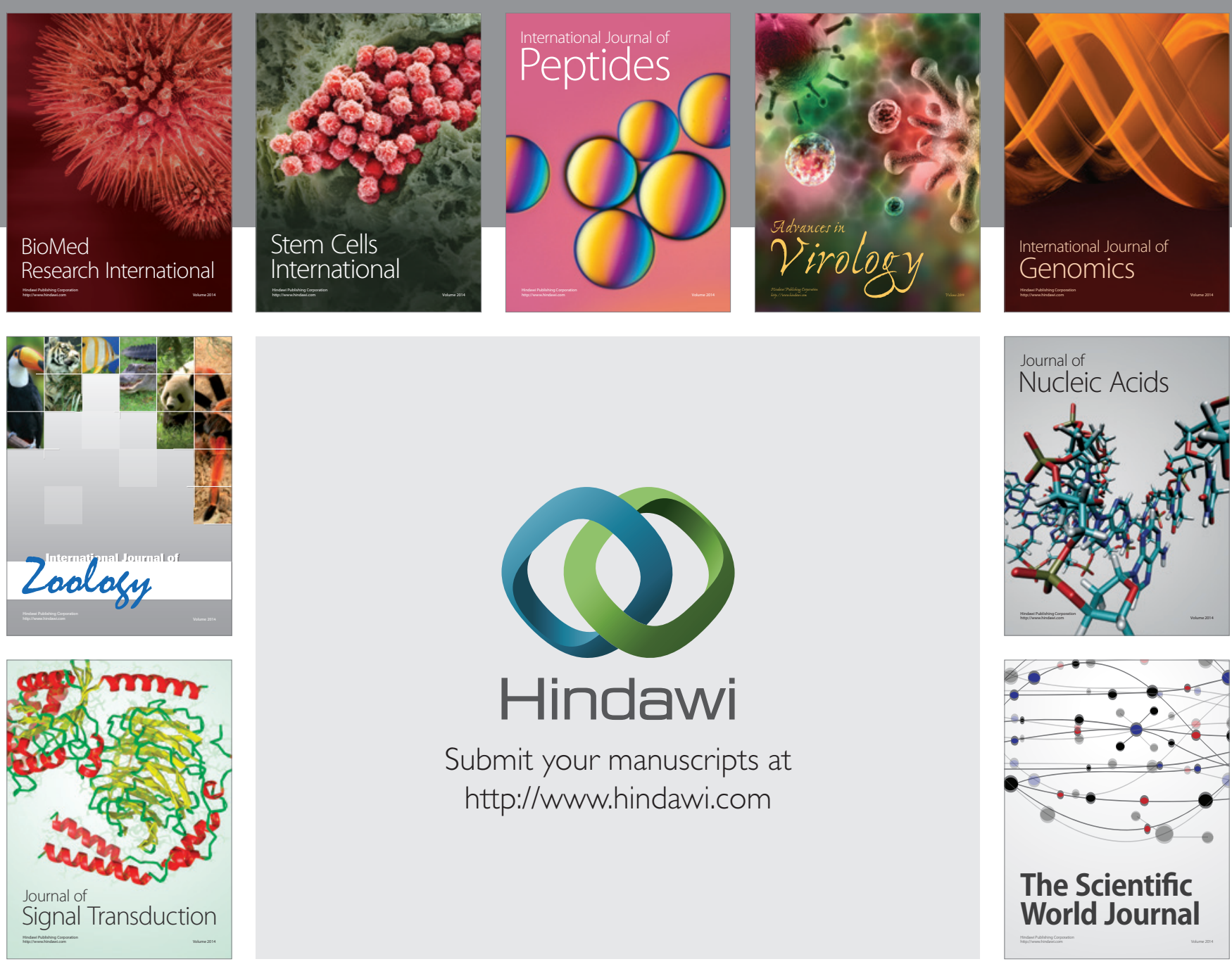

Submit your manuscripts at

http://www.hindawi.com
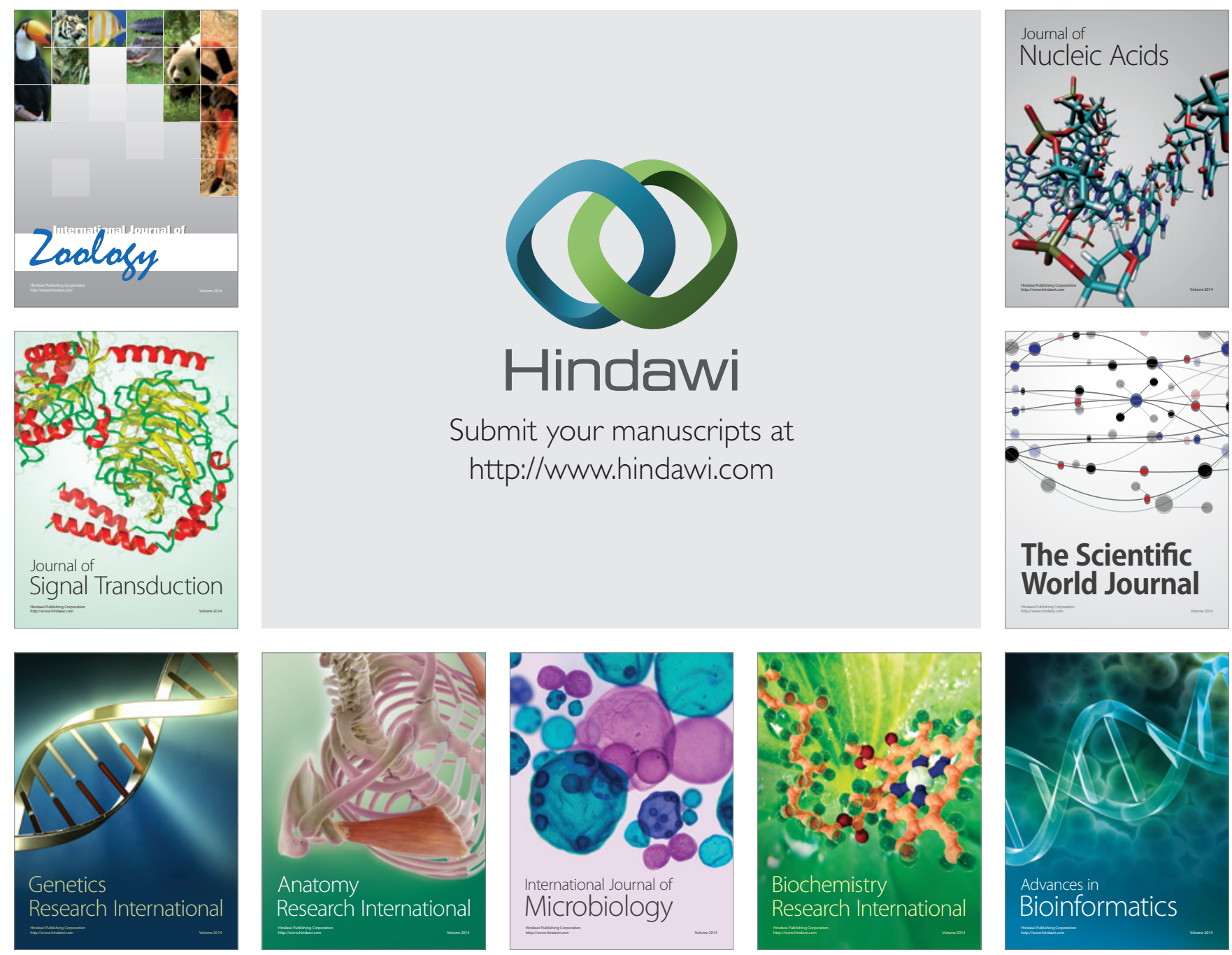

The Scientific World Journal
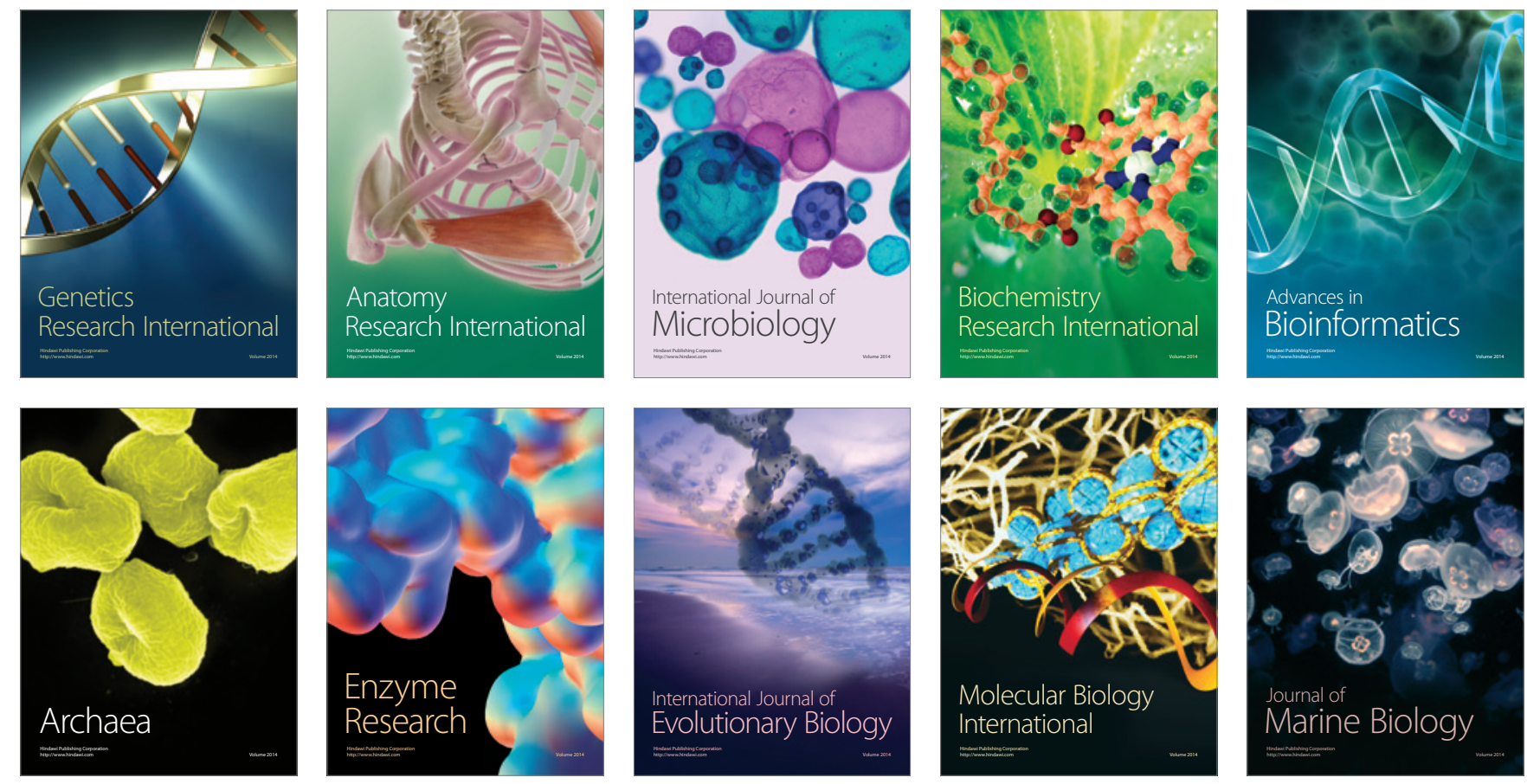